\title{
A formação continuada dos docentes do Proeja/ FIC/Pronatec na Rede Municipal de Goiânia: os desafios do fazer coletivo
}

\author{
Miriam Fábia Alves* \\ Cláudia Borges Costa**
}

\section{Resumo}

Este artigo pretende discutir a experiência do Proeja/FIC/Pronatec na rede municipal de Goiânia, destacando a formação continuada dos docentes e os desafios do fazer coletivo na implementação de um programa que objetiva a formação geral integrada à educação profissional, para jovens e adultos do ensino fundamental. A pesquisa conta com o acervo documental e bibliográfico e tenciona problematizar o papel da formação continuada na implantação desse fazer pedagógico na rede municipal de Goiânia. Essa ação conta com a participação efetiva da Secretaria Municipal de Educação de Goiânia, Faculdade de Educação da Universidade Federal de Goiás e do Instituto Federal de Educação, Ciência e Tecnologia de Goiás. O programa está sendo implantado em dez escolas da rede municipal da educação que retomam uma tradição de formação e fazer coletivo que abre possibilidade para a sustentaçáo de uma política de formação geral integrada à educação profissional para jovens e adultos trabalhadores

Palavras-chave: Educação de Jovens e Adultos. Formação Continuada. Educação Profissional.

\footnotetext{
*Doutora em Educação pela Universidade Federal de Minas Gerais (UFMG). Professora da Faculdade de Educação e do Programa de Pós-Graduação em Educação da Universidade Federal de Goiás (UFG).

${ }^{* *}$ Mestre em Educação pela Pontifícia Universidade Católica de Goiás (PUC-Goiás). Doutoranda em Educação pela Universidade de Brasília (UNB).
} 


\section{Introdução}

Este artigo pretende discutir a experiência do Proeja FIC/Pronatec na rede municipal de Goiânia, problematizando o papel da formação continuada dos docentes na implementação de um programa que objetiva a formação geral integrada à educação profissional, para jovens e adultos do ensino fundamental.

Discute-se a formação inicial de jovens e adultos trabalhadores no ensino fundamental da rede municipal de Goiânia, numa proposta que advém da possibilidade aberta pelo Programa Nacional de Integração da Educação Profissional com a Educação Básica na Modalidade de Educação de Jovens e Adultos (Proeja), conforme prevê o decreto no. 5.840, de 2006 (BRASIL, 2006). O programa vem sendo oferecido desde 2013 para dez escolas municipais contando com a participação efetiva da Secretaria Municipal de Educação (SME) de Goiânia, Faculdade de Educação da Universidade Federal de Goiás (UFG/FE) e do Instituto Federal de Educação, Ciência e Tecnologia de Goiás.

Sendo assim, este artigo tem como referências a textos publicados e documentos produzidos sobre o tema, contando também com a experiência de uma das autoras que tem acompanhado esse fazer pedagógico na rede municipal de Goiânia. A discussão refaz a trajetória histórica mal sucedida da política de profissionalização instituída pela reforma Lei $n^{\circ}$ 5.692/1971 (BRASIL, 1971), retomando os fatores primordiais que ocasionaram esse fracasso. Em seguida, discute-se a implantação da experiência de formação inicial no ensino fundamental com formação profissional na rede municipal de Goiânia e por fim focaliza a formação continuada dos professores na proposta de um fazer coletivo que vislumbre uma possibilidade de formação integrada do trabalhador.

\section{A profissionalização compulsória: a reforma de 1971}

No Brasil a educação profissional tem sido utilizada como projeto formativo para atender às camadas populares e recentemente tem sido apropriada nos discursos governamentais como necessidade do desenvolvimento do país e das demandas do capital.

Se retomarmos as décadas de 1960 e 1970, período em que o Brasil viveu sob o regime de ditadura militar (1964-1985), podemos perceber que a reforma do $2^{\circ}$ grau, realizada por meio da Lei no 5.692/1971 tinha um forte alinhamento com a teoria do capital humano (BRASIL, 1971). Para Saviani (2008, p. 296), houve uma 
[...] ênfase nos elementos dispostos pela "teoria do capital humano"; na educação como formação de recursos humanos para o desenvolvimento econômico dentro dos parâmetros da ordem capitalista; na função de sondagem de aptidóes e iniciação para o trabalho atribuída ao primeiro grau de ensino; no papel do ensino médio de formar, mediante habilitaçóes profissionais, a mão-de-obra técnica requerida pelo mercado de trabalho; na diversificação do ensino superior, introduzindo-se cursos de curta duração, voltados para o atendimento da demanda de profissionais qualificados; no destaque conferido à utilizaçáo dos meios de comunicação de massa e novas tecnologias como recursos pedagógicos; na valorização do planejamento como caminho para racionalização dos investimentos e aumento de sua produtividade; na proposta de criação de um amplo programa de alfabetização centrado nas açóes das comunidades locais.

Nesse contexto, a reforma do $2^{\circ}$ grau ganha relevância ao atrelar a formação geral dos estudantes à profissionalização. Analisando essa vinculação direta da educação às necessidades do mercado, Saviani (2008, p. 295) afirma que "o ensino médio teria como objetivo a preparação dos profissionais necessários ao desenvolvimento econômico e social do país". Assim, a mudança curricular proposta na reforma estabelecia que no currículo do $2^{\circ}$ grau deveria predominar a chamada formação especial com habilitação profissional:

Art. 5o As disciplinas, áreas de estudo e atividades que resultem das matérias fixadas na forma do artigo anterior, com as disposiçóes necessárias ao seu relacionamento, ordenação e sequência, constituirão para cada grupo currículo pleno do estabelecimento.

$\$ 1^{\circ}$ Observadas as normas de cada sistema de ensino, o currículo pleno terá uma parte de educação geral e outra de formação especial, sendo organizado de modo que:

a) no ensino de primeiro grau, a parte de educaçáo geral seja exclusiva nas séries iniciais e predominantes nas finais; 
b) no ensino de segundo grau, predomine a parte de formação especial.

$\$ 2^{\circ}$ A parte de formação especial de currículo:

a) terá o objetivo de sondagem de aptidôes e iniciarão para o trabalho, no ensino de lo grau e de habilitação profissional, no ensino de $2^{\circ}$ grau;

b) será fixada, quando se destine a iniciação e habilitação profissional, em consonância com as necessidades do mercado de trabalho local ou regional, à vista de levantamentos periodicamente renovados. (BRASIL, 1971).

Essa obrigatoriedade, cumprida em larga escala pelas redes públicas, ganhava uma excepcionalidade "o caráter de aprofundamento em determinada ordem de estudos gerais para atender a aptidão específica do estudante, por indicação de professores e orientadores" (BRASIL, 1971), que acabou beneficiando especialmente a rede privada que manteve seus cursos preparatórios para o ensino superior a qual era atribuído "as funçóes de formar a mão-de-obra especializada requerida pelas empresas e preparar os quadros dirigentes do país" (SAVIANI, 2008, p. 295).

Observamos que a reforma preconizava a terminalidade do $2^{\circ}$ grau, que formaria a máo de obra para atender às demandas do mercado de trabalho. No entanto, essa profissionalização proposta na reforma do $2^{\circ}$ grau fracassou devido a muitos fatores. Para Domingues, Toschi e Oliveira (2000, p. 64), a ausência de financiamento foi decisiva:

No Brasil, apesar da importância que os governos dão ao planejamento curricular, a história tem demonstrado que, sucessivamente, as reformas "fracassam”. É o que demonstra a maioria dos estudos acerca, por exemplo,

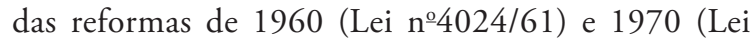
$\mathrm{n}^{\mathrm{o}}$ 5692/71). Por que elas fracassaram? Será que os mesmos equívocos se repetem na atual reforma do Ensino Médio? Naquelas, o insucesso se deveu, basicamente, à ausência de financiamento do processo de manutenção e investimento e à falta de uma política "agressiva" de formaçáo de professores e de recursos humanos em 
geral. Deveu-se também à ausência de uma política de adequaçáo do espaço e da infra-estrutura pedagógica, além da inexistência de uma política editorial que superasse o passado.

No caso da reforma de 1971, para implementar a profissionalização precisaria de um investimento maciço na formação do corpo docente para atender a oferta de cursos profissionalizantes, melhoria e reformas da infraestrutura das escolas, recursos para laboratórios e equipamentos, que não foram contemplados. No estudo realizado no estado do Paraná, Valério (2007, p. 92) afirma que a proposta de profissionalização não se implementou efetivamente, pois

[...] as condiçóes de infra-estrutura eram precárias e somente as escolas-pilotos é que possuíam materiais e laboratórios específicos aos cursos. Pela lei, o estabelecimento de ensino é que escolhia os cursos técnicos que iria ofertar, segundo a demanda do mercado em seu entorno. Não foi essa, porém, a orientação que prevaleceu, e as escolas passaram a ofertar cursos que não demandassem muitos recursos, pela falta de estrutura.

A reforma de 1971, na esteira do que vinha ser a educação profissional no Brasil, aprofunda ainda mais a perspectiva de que aos filhos dos trabalhadores deveria ser ofertada uma educação preparatória para o exercício de uma profissáo, mesmo que essa formação acontecesse nas condiçóes mais precárias. Assim, a formação era uma mescla dos conteúdos gerais (ministrados nas escolas privadas) com os conteúdos de formação para o trabalho. Uma mistura que não garantia aos estudantes uma sólida formação geral, ou mesmo uma sólida educação profissionalizante.

Diante dessa situação, a Lei n. ${ }^{\circ} 7.044$, de 1982, revogou a compulsoriedade da profissionalização prevendo que a "preparação para o trabalho, no ensino de $2^{\circ}$ grau, poderá ensejar habilitação profissional, a critério do estabelecimento de ensino" (BRASIL, 1982). No entanto, as redes públicas ainda mantiveram muitos de seus cursos de formação técnica, realidade que se alterou em larga medida após a Lei de Diretrizes e Bases (LDB), no 9.394/1996, quando foram estabelecidas novas finalidades para a educação básica e a profissionalização torna obrigatória no $2^{\circ}$ grau, torna-se o ensino médio a "preparação básica para 
o trabalho e a cidadania do educando, para continuar aprendendo, de modo a ser capaz de se adaptar com flexibilidade a novas condiçôes de ocupação ou aperfeiçoamento posteriores" (BRASIL, 1996).

Compreender esse movimento realizado na década de 1970 nos impulsiona a questionar a profissionalização que pretendemos ofertar nas escolas de educação básica nos dias atuais e em como oferecer educação profissional sem incorrer nos erros que marcaram essa experiência tăo recente.

\section{A profissionalização na rede municipal de educação de Goiânia: construindo parcerias}

A rede municipal de educação de Goiânia vem construindo uma proposta de educaçáo que considera o trabalho coletivo em sua dinâmica cotidiana, assim como o quadro técnico da Secretaria Municipal de Educação, vem a alguns anos considerando a realidade vivenciada com os sujeitos educandos da modalidade de Educaçáo de Jovens e Adultos (EJA) para refletir e construir uma alternativa de educação escolar que pudesse enxergar os jovens e os adultos inseridos em um contexto adverso. Essa realidade impóe, dia após dia, a busca da produçáo concreta da existência desses sujeitos e a elaboraçáo de uma proposta de educaçáo que parta dessa situaçáo e produza mudanças na vida desses sujeitos.

Essa perspectiva possibilitou a construção de uma Proposta Política Pedagógica que buscou dialogar com o mundo do trabalho, ou seja, com a realidade dos educandos da modalidade de EJA. Conforme afirma Freire (2004), a educação é uma maneira de interferir na sociedade, daí a importância de conhecer a realidade. Nesse sentido, é imprescindível que a educação seja uma ferramenta para possibilitar a crítica e, dessa forma, o educando seja protagonista de seu tempo.

Em 2005, o governo federal publicou o Decreto no 5.478, que criou o Programa Nacional de Integração da Educação Profissional com a Educação Básica na Modalidade de Educação de Jovens e Adultos (Proeja). Depois de acirrados debates, houve a promulgaçáo do Decreto no 5.840 , de 13 de julho de 2006 (BRASIL, 2006). Nesse novo decreto, ampliava-se a oportunidade de ofertas de cursos nos sistemas estaduais, municipais e entidades nacionais de serviço social, propiciando a integraçáo dos cursos de formação inicial também no ensino fundamental na modalidade de EJA, o que resultou entáo na criaçáo 
do Proeja-FIC (BRASIL, 2007) ${ }^{1}$.

Em 2009, a Secretaria Municipal de Educação de Goiânia entrou em contato com o Instituto Federal de Educação, Ciência e Tecnologia de Goiás (IFG), com o objetivo de firmar a parceria e concorrer ao Edital Proeja-FIC. O projeto aprovado teve início em agosto de 2010, com desafio de integrar o ensino fundamental à qualificação profissional inicial com o curso em Alimentação. A Escola Municipal em Tempo Integral Jardim Novo Mundo, na região Leste de Goiânia - Setor Jardim Novo Mundo, foi escolhida para acolher esse curso. A opção, conforme Projeto Pedagógico da Rede Municipal de Goiânia, ficou estabelecida em 1.700 horas de carga horária total, sendo 1.400 de formação geral e 300 horas de formação inicial e continuada/qualificação profissional ${ }^{2}$.

A experiência vivenciada trouxe a marca da construção coletiva em que envolvia desde os educandos até os parceiros, entre os demais sujeitos do processo. $\mathrm{Na}$ avaliação dos educandos e educadores houve um crescimento de todos os envolvidos no projeto. A discussão do currículo integrado permeou os cursos de formação realizados pelos educadores, bem como os momentos formativos e de planejamento realizados no interior da escola. O grande desafio ocorreu no sentido de entrelaçar os componentes curriculares da educação básica com os conhecimentos da educação profissional. Com essa perspectiva, com base nos eixos temáticos apresentados no projeto pedagógico, buscou-se uma linha metodológica que pretendia concretizar a dimensão inseparável entre trabalho, ciência e cultura.

No decorrer do curso muitos trabalhos, oficinas e festivais gastronômicos contaram com a participaçáo e envolvimento dos educadores e educandos do Curso em Alimentação. Como o resultado demonstrou aspectos positivos da proposta do currículo integrado e, ao mesmo tempo, reafirmou o desafio em se concretizar essa concepção. Em 2013, iniciou-se uma nova parceria, para a $\mathrm{SME}^{3}$ e IFG dando continuidade ao projeto de 2010, agora com a inserção da Universidade Federal de Goiás, por meio da Faculdade de Educação. Ampliouse a perspectiva do PROEJA-FIC para mais nove escolas da Rede Municipal de Educação de Goiânia.

No período de 2011 para 2013 registra-se o novo cenário configurado na política de educação profissional pautada pelo governo da Presidenta Dilma Rousseff que, no início de seu governo, diminuiu os editais e chamadas para abertura de novas turmas/cursos de PROEJA. Surgiu no cenário, com força e volumoso poder financeiro, o Programa Nacional de Acesso ao Ensino Técnico 
e Emprego (Pronatec) ${ }^{4}$. Este passou a ser o programa orientador da educação profissional no Brasil, definindo os novos editais e a alocação de recursos para a profissionalização num modelo de formação rápida e aligeirada.

O Pronatec tem sido alvo de muitas críticas, sobretudo no que diz respeito à fragilidade dos cursos oferecidos, aligeirados, com pouca condição de atender de fato a necessidade dos trabalhadores e muito menos atender ao direito desse cidadão de ter acesso a formação escolar. Outra crítica recorrente ao Pronatec, diz respeito à relação público-privada que conta com a ampla participação do Sistema $S$, que ganha três vezes com a adesão ao Programa. Nas palavras de Guimarães (2014, p. 9):

O fato concreto é que, até agora, o controle dessa formaçáo tem sido das instituiçôes privadas ligadas às mesmas confederaçóes de empresas que demandam essa qualificação. Os $80 \%$ de matrículas do Pronatec realizadas no Sistema $S$ até agora estão distribuídas assim: $43 \%$ no Senai, que é ligado à Confederação Nacional da Indústria (CNI); 30\% no Senac, da Confederação Nacional do Comércio (CNC); 4\% do Senat ligado à Confederação Nacional do Transporte (CNT) e 3\% do Senar, da Confederaçấo Nacional da Agricultura e Pecuária no Brasil (CNA). "As empresas ganham três vezes. Primeiro, pelo subsídio do governo que já existe para o Sistema $S$. Segundo, porque é subsidiado de novo pelo Pronatec. E ganha uma terceira vez porque aproveita essa mão de obra formada ou, se não aproveita, tem a sua disposição um exército industrial de reserva”, analisa Marise Ramos.

Pode se afirmar também que a concepção orientadora desse programa está na mão do Sistema $S$ e ao contrário de defender a integração entre a formação profissional com a educação básica, esse sistema reafirma a visão de cursos rápidos, sem a preocupação com o direito à educação (GUIMARÁES, 2012)

No início deste texto discutimos que a Lei 5.692/71 (BRASIL, 1971) incentivava a predominância da formação para habilitação profissional. O que se percebe, resguardada as diferenças e os contextos de dois períodos históricos, o primeiro na ditatura militar e hoje no governo democrático popular, que o Pronatec é uma atualizaçáo da proposta de qualificação de 1971 para jovens e adultos, mantendo uma concepção de formação profissional como formação 
puramente técnica, capaz de atender às demandas mais emergentes do mercado por mão de obra qualificada. O discurso adotado nos dois momentos históricos, revela que a formação profissional tem como único objetivo suprir as demandas de máo de obra, seja para o desenvolvimento do país, como em 1971, seja para evitar o apagão de mão de obra, nos dias atuais. Para realizar tal intento, o governo legitima a formação aligeirada, o repasse de recursos públicos para a iniciativa privada ofertar cursos de qualidade duvidosa, não investindo sistematicamente em uma politica pública de longo prazo que consolide uma formaçáo profissional aos trabalhadores que promova a sua capacitaçáo, mas também a formação humanística e emancipadora.

Constatamos que atualmente os jovens filhos dos trabalhadores enfrentam condiçóes muito adversas para serem inseridos no mundo do trabalho. Essa situação tem se agravado para os jovens que não concluíram a educação básica, uma vez que a estes resta a possibilidade do sustento por meio do trabalho informal. Nessa situação, convém indagar se o Pronatec conseguiria cumprir com a garantia do direito à educação para todos como assegura a Constituição Federal de 1988(BRASIL, 1988) e LDB no 9.394 (BRASIL, 1996), ou apenas reforça a formação para atender ao mercado de trabalho.

Em meio a essas contradiçóes, as dez escolas da rede municipal de Goiânia que desenvolviam a proposta da formação integrada passaram a ser financiadas com recursos do Pronatec, mas com o desafio de manter os princípios da formação integral e a defesa do currículo integrado, como proposto no Documento Base do Proeja (BRASIL, 2007), a experiência passa a ser chamada Proeja/FIC/Pronatec. $\mathrm{Na}$ esteira da reflexão do projeto, elaborado para a primeira turma do PROEJAFIC na Rede Municipal de Goiânia, os jovens e adultos são compreendidos como sujeitos históricos. Com esse entendimento, objetiva-se contribuir para que cada um construa sua identidade subjetiva por meio de um constante diálogo com a sociedade, mesmo diante dos desafios inerentes à atual heterogeneidade cultural. Os educandos sáo sujeitos de experiências e com direito aos conhecimentos científicos que devem integrar com o mundo do trabalho e da cultura, pois assim se constrói conhecimento e sujeitos com condições de conquistarem sua emancipação social. Nesse sentido, no projeto a cultura:

[...] deve ser vista a partir do ideário político em que os conflitos, as contradiçóes e contestaçóes fazem parte do cenário. Elementos de resistência tornam-se importantes na medida em que formam um conjunto de experiências 
vivenciadas pelos alunos, que são considerados sujeitos participantes da formação. Seguindo essa linha de pensamento, a cultura é percebida como uma produção dialética do trabalho. (GOIÂNIA, 2009, p. 26).

A nova etapa da parceria entre SME e IFG, ganhou a inserção da Faculdade de Educaçáo da UFG e as negociaçóes e articulaçóes para a criaçáo dos cursos iniciaram-se em junho de 2012. Realizou-se um cronograma de açôes em que a SME encarregou-se de buscar adesão das escolas interessadas em assumir a educação básica integrada à educação profissional. Ao IFG coube a organização do Edital para contrataçáo dos profissionais que iriam trabalhar nas escolas com a formação profissional e a UFG começou a traçar e organizar a formação desses profissionais na perspectiva de contribuir com o trabalho a ser desenvolvido diretamente nas escolas que iriam aderir ao projeto.

A demanda pelos cursos apresentou diferenças nas dez escolas. Nesse sentido, foram realizados diálogos com as escolas que, juntamente com seu coletivo de profissionais e toda a comunidade escolar, definiram seus interesses, disponibilidades e escolha dos cursos a serem ofertados. Algumas iniciaram com quatro ou cinco turmas, enquanto outras demandaram esforços em busca de matrículas dos estudantes. Tanto a SME quanto os coletivos de professores e demais profissionais das escolas se empenharam para isso.

Algumas escolas buscaram divulgar os cursos com carro de som, panfletos e mobilização nos bairros, inclusive buscando feiras, igrejas e estabelecimentos comerciais. Essa dinâmica contribuiu para a primeira etapa pedagógica, isto é, os professores puderam se aproximar da comunidade, produzir os conhecimentos para contribuir na realizaçáo inicial de investigaçóes diagnósticas e compor o perfil e a realidade dos jovens e adultos dos respectivos bairros. Conforme Freire (2004, p. 68), "a nossa educabilidade bem como a nossa inserção num permanente movimento de busca em que, curiosos e indagadores, não apenas nos damos conta das coisas mas também delas podemos ter um conhecimento cabal". Esse conhecimento é imprescindível para desenvolver um trabalho significativo na EJA.

A parceria assegurou dois dias a mais do que o previsto no calendário comum da SME para o planejamento coletivo inicial ${ }^{5}$ específico das dez escolas. Logo no início dos encontros de formação, a Divisão de Educação Fundamental - Adolescentes Jovens e Adultos (DEF-AJA) apresentou uma proposta de 
organização para as dez escolas, com orientaçóes preliminares que, mesmo com um caráter inacabado e de construção processual, forneceu orientaçôes básicas para o início das aulas.

Nessa trilha, a parceria tem sido consolidada. Muitos desafios estão sendo enfrentados nas várias vertentes, desde o âmbito da estrutura até a construção da política pedagógica desenvolvida nas escolas. A discussão da formação dedicada aos professores e demais envolvidos no projeto é condição necessária para que o projeto seja desenvolvido, pois essa formação de caráter contínuo é um dos instrumentos que poderá contribuir para que a escola seja carregada de significado para os adolescentes, jovens e adultos trabalhadores.

\section{A formação continuada de professores: os desafios do fazer coletivo}

A formação continuada está sendo um processo construído de forma processual e coletiva. Inicialmente os encontros aconteceram, alternadamente, com a reuniáo de todos os profissionais das dez escolas, nas dependências da Faculdade de Educação e, diferentemente, também com a ida de duplas de orientadores/as às escolas. Os encontros, tanto com o coletivo dos profissionais quanto os encontros nas escolas, foram (ainda são) oferecidos em horário de trabalho, sob a responsabilidade de uma equipe de formação composta por professores da UFG/FE e do IFG, juntamente com a SME (DEF-AJA, URE e CEFPE).

Importante registar que a proposta da formação fundamentou-se na reflexão, tomando como ponto de partida três caminhos: o contexto da sociedade, as vivências dos trabalhadores estudantes nas salas de aula e alguns teóricos que apontam conceitos imprescindíveis e que dialogam com a prática do fazer pedagógico. Nesse sentido, a argumentação de Paulo Freire (2004, p. 38-39) contribui para explicitar essa relaçâo entre conhecimento e realidade, entre pensar e fazer, pois:

A prática docente crítica, implicante do pensar certo, envolve o movimento dinâmico, dialético, ente o fazer e o pensar sobre o fazer._[...] o que se precisa é possibilitar, que, voltando-se sobre si mesma, através da reflexão sobre a prática, a curiosidade ingênua, percebendo-se como tal, se vá tornando crítica. [...] Por isso é que, na formação 
permanente dos professores, o momento fundamental é o da reflexão crítica sobre a prática.

Faz-se necessário, também, registrar a concepção emancipatória de educação defendida no processo de formação dos profissionais e que permeia toda a proposta. Sendo assim, buscou-se o trabalho para dialogar com a educação. Como na reflexão de Sader (2005, p. 17), ao pensar a educação na perspectiva emancipatória "não poderia senão restabelecer os vínculos - tão esquecidos - entre educação e trabalho, como afirmando: digam-se onde está o trabalho em um tipo de sociedade e eu direi onde está a educação". O debate que surge em consequência dessa conversa torna-se necessário principalmente pela atual configuração da globalização econômica posta para sociedade. Os ditames do neoliberalismo estruturado sob a égide da hegemonia financeira capitalista, aliada a adoção de uma política de formação para as competências e para a produtividade interferem no processo educacional para crianças, adolescentes, jovens e adultos desse país.

Os sujeitos educandos da EJA carregam marcas de uma profunda desigualdade social. São jovens e adultos que fazem parte do contingente de subempregados e desempregados do país. São mulheres e homens que, com sua experiência histórica, política, cultural e social, retornam às escolas para dar continuidade aos seus estudos, sobretudo por exigência do mercado de trabalho. Enfim, são sujeitos que retomam o que lhes foi negado pela necessidade de sobrevivência, cujas contradiçôes, ao longo da história, apontam a educação formal como direito de todos e, ao mesmo tempo, as condiçóes reais muito cedo são para eles obrigação de prover a sua subsistência.

A compreensão dessa realidade é fundamental para pensar em formação de professores para EJA. A discussão da concepção de educação que tem permeado os debates na modalidade reporta-se a abordagem gramsciana, em que a formação da cultura geral não pode estar distante da formação para o trabalho.

Preparar as novas geraçóes para o trabalho significa pensar o homem omnilateralmente, na sua totalidade com sua potencialidade de transformar a realidade e não simplesmente submetê-lo ao mundo da produção, tal como afirmaram Engels e Marx (1980, p. 25):

A produção de ideias, de representaçôes e da consciência está em primeiro lugar direta e intimamente ligada à 
atividade material e ao comércio material dos homens; é a linguagem da vida real. As representaçóes, o pensamento, o intercâmbio intelectual dos homens surge aqui como emanação direta de seu comportamento material.

Paulo Freire (1979), no final dos anos 1970, fala de uma educação diferenciada, de uma educação que rompesse com os setores privilegiados da sociedade. Em sua opinião, seria necessária uma educação que não perdesse de vista a "vocação ontológica do homem, a de ser sujeito" (FREIRE, 1979, p. 66), mas que também estivesse atenta à realidade do período, que apresentava sua especificidade de transição para o período democrático. Paulo Freire (1979) aspirava, ainda, a uma educação que inserisse o homem de forma crítica em seu processo histórico e o libertasse, a partir de uma prática conscientizadora, enfim, que possibilitasse ao ser humano a busca de sua capacidade crítica de opinar e decidir como ser humano e coletivo.

A educação baseada na ótica emancipadora assinala uma crítica constante à realidade social em que os homens estáo inseridos. Propóe, dessa forma, que os educandos envolvidos no processo de aprendizagem o façam na medida em que se sintam conscientes de seu papel como educandos/as e sujeitos históricos de uma sociedade. Freire (1979, p. 61) enfatiza a importância do sujeito e seu compromisso com a realidade.

Nenhuma ação educativa pode prescindir de uma reflexão sobre o homem e de uma análise sobre suas condiçôes culturais. Não há educação fora das sociedades humanas e não há homens isolados [...]. Se a vocação ontológica do homem é a de ser sujeito e náo objeto, só poderá desenvolvê-la na medida em que, refletindo sobre suas condiçóes espaço-temporais, introduz-se nelas, de maneira crítica. Quanto mais for levado a refletir sobre situacionalidade, sobre seu enraizamento espaço-temporal, mais "emergerá" dela conscientemente "carregado" de compromisso com sua realidade, da qual, porque é sujeito, não deve ser simples espectador, mas deve intervir cada vez mais.

Na perspectiva de Paulo Freire, é necessário que o homem não esteja somente na realidade, mas esteja com ela, pois assim poderá desenvolver relações 
contínuas que possibilitem criar novos conhecimentos e obter o domínio da cultura. Para Gramsci (2004, p. 53), não é possível separar a atividade intelectual da ação que os homens realizam e, dessa forma, vislumbra o homem como agente de uma concepção de mundo.

Não há atividade humana da qual se possa excluir toda intervenção intelectual, não se pode separar o homo faber do homo sapiens. Em suma, todo homem, fora de sua profissão, desenvolve uma atividade intelectual qualquer, ou seja, é um 'filósofo', um artista, um homem de gosto, participa de uma concepção do mundo, possui uma linha consciente de conduta moral, contribui, assim, para manter ou para modificar uma concepção do mundo, isto é, para suscitar novas maneiras de pensar.

O debate atual aponta a educação em uma disputa em campos opostos, isto é, de um lado o projeto de educação que se afirma na formação das competências de cunho neoliberal, apoiando a formação de professores que também assuma as novas configurações do capitalismo e do mercado. Em oposição a essa política neoliberal, a formação humana gramsciana se coloca como alternativa de educação que retoma o trabalho como natureza central. $\mathrm{O}$ que significa pensar uma formação de educadores, principalmente de EJA, que possa desvelar aos trabalhadores estudantes as inúmeras reflexóes pertinentes ao mundo do trabalho, bem como as contradiçóes estabelecidas pelo mercado neoliberal e que continua sustentando essa sociedade desigual.

Nessa proposta de formação os registros das reflexóes são considerados imprescindíveis. Na perspectiva da construção coletiva desse processo formativo e para as possibilidades de estruturação de um currículo diferenciado que aborde o mundo do trabalho, diálogo entre teoria e prática, interdisciplinaridade, regência compartilhada, salas operacionalizadas para tempos e aprendizagem diferenciados, bem como avaliaçóes diagnósticas continuadas.

Com tais perspectivas, a equipe de formação orienta os participantes para a pesquisa sobre materiais didáticos e de referência para a formação continuada dos professores, oferecendo farto material bibliográfico, inclusive orientando para a busca também nos portais ${ }^{6}$ dos Fóruns de EJA?

Diferentemente dos chamados "pacotes" de formação continuada, que hoje são oferecidos/impostos às redes municipais, a proposta de formação 
que está sendo realizada parte da realidade concreta dos professores e do seu trabalho na experiência de implantação da formação geral e formação profissional. Feito no chão da escola e a partir das demandas cotidianas que o curso apresenta o trabalho coletivo se faz como um dos elementos fundamentais para a consolidaçáo da experiência que está sendo realizada na rede municipal de Goiânia.

\section{Algumas considerações finais}

A década de 1990 foi cenário de disputa de projetos educacionais, tanto na educação básica como na educação profissional. Que projeto de educação o país assumiu? Qual era a perspectiva de educação básica assumida pelo estado brasileiro? Qual o papel da educação profissional na formação dos jovens e adultos brasileiros? A legislaçáo brasileira, desde a LDB, revela as nuances dessa disputa e nesse período as tentativas de romper, ainda que de forma tímida, com o caráter de treinamento compulsório determinado pelos governos militares na década de 1970.

No entanto, a educação profissional foi apropriada pelos governos neoliberais, que trouxe como doutrina a pedagogia das competências e o discurso da empregabilidade, com acentuada restriçáo aos direitos de igualdade de todos e ênfase a um pretenso direito individual e subjetivo.

No campo da Educação de Jovens e Adultos e da Educação Profissional (EP), a organizaçáo dos movimentos sociais exigia a responsabilidade do poder público na oferta da educaçáo básica para jovens e adultos que por inúmeros motivos, não tiveram acesso à escolarização ou dela estiveram afastados por muitos anos. A denúncia das frágeis ações descontínuas voltadas para jovens e adultos e a resistência ao conformismo e ao caráter de formação para subalternos, foram elementos que pressionaram o contexto das políticas de cunho neoliberal.

Professores, alunos e sindicatos, entre outros segmentos, organizaram movimentos de oposição que propiciaram debates acerca da educação básica como componente fundamental da qualificação profissional dos trabalhadoresalunos, jovens e adultos. Essa reivindicaçáo apontava a necessidade de assegurar de forma concreta a integração e valorização da escolaridade, sem excetuar a política de educação de jovens e adultos.

Concretamente essa reivindicação só foi atendida, ainda assim, por meio de um programa a partir da primeira gestáo do governo Lula, em que o processo 
de integração entre EJA e EP se torna possível com a criação do Programa Nacional de Integração da Educação Profissional com a Educação Básica na Modalidade de Educação de Jovens e Adultos (Proeja).

Nesse contexto, o projeto pedagógico que está em curso em Goiânia tem a marca da construção coletiva de uma parceria entre SME, IFG e FE/ UFG. As dez escolas tem vivenciado o compromisso e o desafio em atender a demanda de jovens e adultos trabalhadores com uma proposta pedagógica que busca integrar a formação da educação fundamental com os conteúdos da educação profissional.

A formação dos educadores prevista no projeto pedagógico tem perseguido o diálogo com a prática educativa no chão das salas de aula, tem buscado a retomada da centralidade do trabalho, o que possibilita aos trabalhadores estudantes o sentido de pertencimento ao espaço escolar e aproximação com a formação básica. A formação tem feito o esforço de apropriar do debate do trabalho, enquanto produção travada nas relações contraditórias do mercado capitalista e também como constituiçâoo humana, produzida historicamente.

Compreendida numa perspectiva gramsciana, a formaçáo continuada dos professores que estão envolvidos no Proeja/FIC/Pronatec, busca realizar uma interlocuçáo com a realidade vivenciada pelos professores e os desafios em fazer acontecer um projeto de formação que integre vida, escola e trabalho numa perspectiva transformadora.

\section{Notas}

${ }^{1}$ O Documento Base Proeja-FIC (BRASIL, 2007), Formação Inicial e Continuada (FIC) no âmbito do Ensino Fundamental, assinala a possibilidade de se constituir referenciais que propiciem a unidade das especificidades da formação profissional inicial e do segundo segmento do ensino fundamental da EJA.

${ }^{2}$ A carga horária mínima prevista no Documento Base para conclusão do curso era de 1.200 horas para formação geral e 200 horas para formação profissional (BRASIL, 2007).

${ }^{3}$ A Rede Municipal de Educação de Goiânia está sob a gestão da professora Neide Aparecida da Silva, Secretária Municipal de Educaçáo, e do prefeito Paulo Garcia, do Partido dos Trabalhadores (PT), reeleito pela coligação 
"Cidade Sustentável" (PRB / PDT / PT / PMDB / PTN / PR / PSDC / PRTB / PSB), para a gestão 2013-2016.

${ }^{4}$ Conforme Castioni (2013, p. 37), "A presidenta Dilma, cumprindo uma das suas promessas de campanha, apresentou ao Congresso Nacional o Projeto de Lei n. 1209, de 29 de abril de 2011, que cria o Programa Nacional de Acesso ao Ensino Técnico e Emprego (PRONATEC). Foi aprovado pelo Congresso Nacional e transformado na Lei n. 12.513, de 26 de outubro de 2011 (BRASIL, 2011). O PRONATEC tem o objetivo de: i) ampliar as vagas e continuar a expansão da Rede Federal de Educaçáo Profissional e Tecnológica; ii) fomentar a ampliação de vagas das redes estaduais de Educação Profissional; iii) incentivar a ampliação de vagas e a expansão da rede física de atendimento do Sistema $S$; e iv) fomentar a expansão da oferta de Educação Profissional e Técnica de nível médio na modalidade de educação a distância”.

${ }^{5}$ A equipe de formação composta pelas instituiçôes parceiras, nesse primeiro encontro, discutiu sobre os seguintes temas: PROEJA e PRONATEC, programas do governo federal: o que são?; PROEJA-PRONATEC da SME: o que estamos construindo?; Sujeitos estudantes trabalhadores da EJA; Concepção de educação e fundamentos do currículo integrado; Discussão acerca do material didático: um olhar sobre o material da CUT; Formação continuada; Contratações pelo IFG; Organização da escola e organização das turmas; Carga horária; Requisitos de escolaridade para os estudantes; Frequência, transferência ou desistência do curso; Registro diário de turmas; Avaliação; Planejamento.

${ }^{6}$ Disponível em: <www.forumeja.org.br>.

${ }^{7}$ Os Fóruns de EJA foram criados a partir de 1996 e, de acordo com Machado (2008, p. 169), "Esse movimento, de 1996 até os dias atuais, promoveu a mobilização dos diversos estados da federação, sendo que os fóruns, hoje, estão presentes em todos eles e no Distrito Federal, constituindo-se, em alguns estados, por uma organização descentralizada em vários fóruns regionais".

\section{REFERÊNCIAS}


BRASIL. Lei no 5.692, de 11 de agosto de 1971. Fixa Diretrizes e Bases para o ensino de $1^{\circ}$ e $2^{\circ}$ graus, e dá outras providências. Diário Oficial da União, Brasília, DF, 12 ago. 1971. Disponível em: <http://www.planalto.gov.br/ ccivil_03/leis/L5692impressao.htm>. Acesso em: 21 jan. 2014.

Lei no 7.044 , de 18 de outubro de 1982. Altera dispositivos da Lei $\mathrm{n}^{\mathrm{o}}$ 5.692, de 11 de agosto de 1971, referentes a profissionalização do ensino de $2^{\circ}$ grau. Diário Oficial da União, Brasília, DF, 19 out. 1982 Disponível em: <http://www.planalto.gov.br/ccivil_03/leis/L7044impressao.htm>. Acesso em: 21 jan. 2014.

Constituição da República Federativa do Brasil 1988. Brasilia, DF, 5 out. 1988.

Lei no 9.394, de 20 de dezembro de 1996. Estabelece as diretrizes e bases da educação nacional. Diário Oficial da Uniáo, Brasília, DF, 23 dez. 1996. Disponível em: <http://www.planalto.gov.br/ccivil_03/leis/19394. $\mathrm{htm}>$. Acesso em: 21. Jan. 2014.

Decreto no 5.840, de 13 de julho de 2006. Institui, no âmbito federal, o Programa Nacional de Integração da Educação Profissional com a Educação Básica na Modalidade de Educação de Jovens e Adultos PROEJA, e dá outras providências. Diário Oficial da União, Brasília, DF, 14 jul. 2006. Disponível em: <http://www.planalto.gov.br/ccivil_03/_ato20042006/2006/decreto/D5840.htm>. Acesso em: 21 jan. 2014.

BRASIL. MEC, SETEC. Documento Base do Programa Nacional de Integração da Educação Profissional com a Educação Básica na Modalidade de Educação de Jovens e Adultos, Brasília, DF, 2007.

. Lei no 12.513 , de 26 de outubro de 2011. Institui o Programa Nacional de Acesso ao Ensino Técnico e Emprego (Pronatec); altera as Leis no 7.998, de 11 de janeiro de 1990, que regula o Programa do Seguro-Desemprego, o Abono Salarial e institui o Fundo de Amparo ao Trabalhador (FAT), no 8.212, de 24 de julho de 1991, que dispóe sobre a organização da Seguridade Social e institui Plano de Custeio, no 10.260, de 12 de julho de 2001, que dispóe sobre o Fundo de Financiamento ao Estudante do Ensino Superior, e no 11.129, de 30 de junho de 2005, que institui o Programa Nacional de Inclusão de Jovens (ProJovem); e dá outras providências. Diário Oficial da Uniāo, Brasília, DF, 27 out. 2011. Disponível em: <http://www.planalto.gov.br/ccivil_03/_Ato20112014/2011/Lei/L12513.htm>. Acesso em: 10 jan. 2014. 
CASTIONI, Remi. Planos, Projetos e Programas de educação profissional: agora é a vez do Pronatec. Revista Sociais e Humanas, Santa Maria, RS, v. 6, n. 1, jan./abr. 2013.

DOMINGUES, José Luiz, TOSCHI, Mirza Seabra; OLIVEIRA, João Ferreira de. A reforma do Ensino Médio: a nova formulação curricular e a realidade da escola pública. Educação \& Sociedade, Campinas, SP, v. 21, n. 70, abr. 2000. Disponível em: <http://dx.doi.org/10.1590/S0101-73302000000100005>.

FREIRE, Paulo. Educação e mudança. 28. ed. Rio de Janeiro: Paz e Terra, 1979.

. Pedagogia da autonomia: saberes necessários à prática educativa. São Paulo: Paz e Terra, 2004.

GOIÂNIA. Secretaria Municipal de Educação. Projeto Pedagógico do Proeja-FIC. Goiânia, 2009.

GRAMSCI, Antônio. Cadernos do cárcere. Tradução de Carlos Nelson Coutinho. Rio de Janeiro: Civilização Brasileira, 2004. V. 2.

GUIMARÃES, Cátia. Rumos da educação profissional. Escola Politécnica de Saúde Joaquim Venâncio, Rio de Janeiro, 19 jan. 2012. Disponível em: <http://www.epsjv. flocruz.br/index.php?Area=Noticia\&Num=599>. Acesso em: 10 jan. 2014.

. Pronatec: qualificação e trabalho sob demanda. Revista POLI: saúde, educaçáo e trabalho, Rio de Janeiro, ano 6, n. 32, p. 4-9, jan./ fev. 2014. Disponível em: <http://www.epsjv.fiocruz.br/upload/ EdicoesRevistaPoli/R39.pdf>. Acesso em: 12 jan. 2014.

MACHADO, Maria Margarida. Formação de professores para EJA: uma perspectiva de mudança. Retratos da Escola. Brasília, DF, v. 2, n. 2, p. 161174, jan./dez. 2008.

MARX, Karl; ENGELS, Friedrich. A ideologia alemã. Tradução de Conceiçáo Jardim et al. Lisboa: Editorial Presença, 1980.

SADER, Emir. Prefácio. In: MÉZÁROS, István. A educação para além do capital. São Paulo: Boitempo, 2005. p. 15-18.

SAVIANI. Dermeval. O legado educacional do regime militar. Caderno Cedes, Campinas, SP, v. 28, n. 76, set./dez. 2008.

VALÉRIO, Telma Faltz. A reforma do $2^{\circ}$ Grau pela Lei 5.692/71 no Paraná: representaçóes do processo. 2007. Dissertação (Mestrado em Educação) Universidade Federal do Paraná, Curitiba, 2007. 


\section{La formación continua de los docentes Proeja/FIC/ Pronatec en la red municipal de Goiânia: los desafíos de una realización colectiva}

\section{Resumen}

Ese artículo pretende discutir la experiencia del Proeja/FIC/Pronatec en la red municipal de enseñanza de Goiânia destacando la formación continua de los docentes y los desafíos de la práctica colectiva en la implementación de un programa que tiene por objetivo la formación general integrada a la educación profesional, para jóvenes y adultos en la enseñanza fundamental. La investigación cuenta con el archivo documental y bibliográfico y busca problematizar el papel de la formación continua y la implementación pedagógica en la red municipal de enseñanza de Goiânia. Esta acción cuenta con la participación efectiva de la Secretaría Municipal de Educación de Goiânia, la Faculta de Educación de la Universidad Federal de Goiás y del Instituto Federal de Educación, Ciencia y Tecnología de Goiás. El programa está siendo implementado en diez escuelas de la red municipal de educación que retoman una tradición de formación y una realización colectiva que abre la posibilidad de sustentación de una política de formación general integrada a la educación profesional para jóvenes y adultos trabajadores.

Palabras claves: Educación de Jóvenes y Adultos. Formación continua. Educación profesional.
The continued education of the teachers of Proeja/FIC/ Pronatec on the municipal network of Goiânia: the challenges of the collective making

\section{Abstract}

This paper aims to discuss the Proeja/FIC/ Pronatec experience on the municipal network of Goiânia, highlighting the continued education of the teachers and the challenges of the collective doing on the implementation of a program that aims at the general education integrated to the professional education, for youth and adults of the elementary education. The research has documentary and bibliographic collection and intends to discuss the role of continued education on the implementation of this pedagogical action on the municipal network of Goiânia. This action has the effective participation of the Municipal Secretary of Education of Goiânia, Faculty of Education of the Federal University of Goiás and Federal Institute of Education, Science and Technology of Goiás. The program is being implemented on ten schools of the municipal network of education, that return a tradition of education and collective doing that opens the possibility to sustain a policy of general education integrated to the professional education for youth and adults workers.

Keywords: Education of Youth and Adults. Continuous education. Professional education. 


\section{Claudia Borges Costa}

E-mail:cbc2111@gmail.com

\section{Miriam Fábia Alves}

E-mail:miriamfabia@gmail.com

Recebido em: 18/11/2013

Versáo final recebida em: 13/1/2014

Aprovado em: 18/1/2014 